\title{
La filosofía de la acción de Paul Ricoeur
}

\author{
ALFREDO MARTÍNEZ SÁNCHEZ
}

Desde 1950 en que, con Le volontaire et l'involontaire, comienza la publicación de su proyectada Filosofía de la Voluntad Ricoeur no ha dejado de atender al mundo de la praxis. Dentro del conjunto de su obra dedicado a la esfera de lo práctico podemos distinguir una filosofía de la acción que se mueve en el plano de una acción que aún no ha sido cualificada ni ética, ni política, ni jurídicamente, pero que mantiene estrechos vínculos con la ética y con las ciencias sociales. Tal filosofía de la acción no ha sido objeto de una elaboración sistemática, sin embargo, puede ser reconstruida siguiendo su pista en la travesía del pensamiento de Ricoeur. De hecho, una buena parte de su producción favorece una lectura guiada por la brújula de la acción, recorriendo una senda que comunique las dos obras mayores que marcan los comienzos y las últimas investigaciones filosóficas del autor: Le volontaire et l'involontaire (1950) y Soi-même comme un autre (1990) (aunque puede ser prolongada en sus últimas publicaciones) ${ }^{1}$. En primer lugar veremos una síntesis panorámica de dicha senda, para considerar posteriormente los rasgos fundamentales que identifican la filosofía de la acción que aflora de ese recorrido, a saber:

(1) Autonomía con respecto a un discurso ético/político (manteniendo valiosos lazos con la ética y con las ciencias sociales).

(2) Evolución que desemboca en una fórmula caracterizada por la conjugación de tres tradiciones filosóficas: fenomenología, análisis del lenguaje, y hermenéutica.

(3) Persistencia en su contenido de determinados núcleos dinámicos, como son la estructura acción/pasión, la conexión agente/acción, y La pasión por lo posible.

\section{LA SENDA DE LA ACCIÓN ${ }^{2}$}

La acción, aun limitada a su sentido pre-é tico y pre- político, constituye una buena brújula para trazar una vía que conduzca desde la primera obra mayor de $\mathrm{P}$. Ricoeur, dedicada expresamente a desarrollar su propio pensamiento ( $L e$ volontaire et l'involontaire), hasta su último y más importante trabajo extenso (Soi-même comme un autre). Esta vía pone de manifiesto que existe una conexión profunda entre ambas obras, y que esa conexión nos permite comprender una buena parte del periplo intelectual del autor, y leer sus resultados, desde la perspectiva de la acción, que se revela como una de sus más permanentes y fructíferas inquietudes.

El vínculo probablemente más patente entre los dos libros lo proporciona el campo de la acción. Así, Le volontaire et l'involontaire aparece como el inicio de una Filosofía de la Voluntad, y aunque sólo la segunda parte está explícitamente dedicada al actuar, en el resto de la obra desempeñan un papel fundamental elementos directamente asociados al campo conceptual de la acción, como la motivación, la decisión, el movimiento corporal, y el problema libertad/necesidad. Por otro lado, ante el carácter fragmentario de los estudios que componen Soi-même comme un autre (en adelante Sí mismo como otro), la acción, en un sentido amplio (l'agir humain), es presentada por Ricoeur como la unidad temática común a todos ellos, 
aunque advierte que se trata de una unidad analógica entre las diferentes acepciones del término. Pero la guía escogida para transitar entre las dos obras seleccionadas se ciñe a la acción en el sentido restringido: una gran parte del trabajo de nuestro autor en torno a la acción humana configura una filosofía de la acción que no es una ética (ni una filosofia política o jurídica), aunque pueda precederla, y en algún momento envolverla. El propio autor ha realizado esta separación en distintas ocasiones, comenzando con la suspensión ejercida sobre la voluntad "mala" o "culpable" en Le volontaire et l'involontaire.

\section{De la Fenomenología de la voluntad a la Filosofía de la acción}

Ricoeur proyectó su Filosofía de la Voluntad en tres fases, la primera de las cuales, como ya hemos visto, coincide con $L e$ volontaire et l'involontaire. El libro se ocupa ampliamente de lo que el autor, siguiendo corrientes filosóficas angloamericanas, posteriormente ha llamado red conceptual de la acción $n^{3}$. Se inician así algunas de las constantes de la aproximación de Ricoeur al mundo de la acción, tales como el maridaje acción/pasión, la preocupación por el problema señalado en la tercera antinomia kantiana (vinculado al de la distinción entre causa y motivo), o la relación acción/agente, que involucrará la noción fundamental de poder (poder-hacer).

En torno al problema causa/motivo es posible establecer una serie de conexiones que nos permitirán articular distintas investigaciones del autor. Por un lado, se relaciona con las nociones de fuerza y sentido, originadas en los estudios sobre Freud y reutilizadas después en un contexto analítico (como en El discurso de la acción $)^{4}$. En el interior de la propia filosofía analítica la distinción entre causa y motivo es paralela a la que se establece entre acción y movimiento. Además, existe otra correspondencia entre la controversia hermenéutica de la explicación y la comprensión y la distinción causa/motivo, en tanto que las relaciones causales pertenezcan al campo propio de la explicación. El mismo título de la obra, y con más claridad el título de la edición inglesa (Freedom and Nature), puede ser incorporado a este plexo ya que la naturaleza ha sido concebida como el reino de la determinación causal, mientras que la libertad y la voluntariedad sólo serían posibles allí donde el motivo "inclina sin determinar" (o "inclina sin necesitar"). En este sentido, la búsqueda de una noción de motivación se corresponde con la necesidad de articular actividad y pasividad (o receptividad).

Aunque Finitud y Culpabilidad ${ }^{6}$ constituye la segunda parte de la Filosofia de la Voluntad, podemos considerar que, desde nuestro punto de vista, no representa la genuina continuación de Le volontaire et l'involontaire en el desarrollo de una filosofía de la acción que no es una ética. Por un lado, porque expresamente levanta el paréntesis que hacía de $L e$ volontaire et linvolontaire una obra con pretensiones descriptivas, e introduce el problema de la voluntad "mala" o "culpable" en un sentido ético (aparte de sus implicaciones ontológicas), por otra, porque sólo indirectamente contribuye a la elaboración de los elementos relevantes en la evolución que esa filosofía de la acción tendrá en Ricoeur ${ }^{6}$. Su importancia, para nosotros, radica sobre todo (junto a ciertos elementos de su antropología) en el papel que desempeña en la formación de la orientación hermenéutica del autor, posteriormente incorporada a sus trabajos sobre la acción.

La verdadera continuación de Le volontaire et l'involontaire será, en este sentido restringido, el curso que Ricoeur imparte durante 1970-1971 en la Universidad de Lovaina con el título Sémantique de l'ac- 
tion, reproducido parcialmente en $E I$ discurso de la acción (cuya versión original en francés, recordemos, es de 1977). En el periodo que separa el primer volumen de la Filosofía de la Voluntad y el curso de 1970-71, podemos seguir la pista que nos interesa en el artículo de 1967 "Philosophy of Will and Action"7, que muestra la continuidad de ciertos núcleos y actitudes, como la preocupación por la motivación, el enfoque acción/pasión, y la conexión agente/acción, e introduce las nociones de fuerza y sentido, así como la necesidad de la interpretación. El autor recoge aquí sus conclusiones sobre el fracaso de la autotransparencia de la conciencia (o en otras palabras, sobre la no inmediatez de la conciencia) derivadas de la lectura de Freud ${ }^{8}$ : no nos conocemos a nosotros mismos de manera inmediata, ni tenemos una intuición inmediata del sentido de nuestra propia vida, por tanto, el sentido inmediato debe ser sustituido por el sentido mediato, es decir, por el sentido interpretado. Por otro lado, la sospecha sobre el testimonio de la conciencia inmediata introduce un factor que en este texto sólo es mencionado, pero cuyos efectos se prolongarán en obras posteriores. Ese factor consiste en la necesidad de introducir mediaciones, y abre la puerta tanto a la mediación por el lenguaje, que en El discurso de la acción vendrá de la mano de la filosofía analítica, como a la exigencia de interpretar el campo motivacional, que, en última instancia, se comunica con la ubicación de la red conceptual de la acción en el contexto hermenéutico.

Los resultados para la fenomenología de la voluntad y de la acción (que son tratadas como una sola) se plasman en la concepciớn de la libertad, la sospecha surgida del fracaso de la conciencia inmediata debe aplicarse a la ilusión de una elección sin motivos, pues el error consiste en vincular la libertad con la ausencia de motivos. De esta manera, el artículo se convierte en un puente entre la noción de motivo de Le volontaire et l'involontaire (los motivos inclinan sin determinar) y la que será desarrollada en EI discurso de la acción (tratando de superar la oposición motivo/causa), enriqueciéndose sucesivamente mediante el diálogo con el psicoanálisis y con la Teoría (analítica) de la acción. En este contexto, lo posible designa la capacidad para la realización del proyecto en la medida en que tal realización está en mi poder. Este posible es distinto de lo posible en los sentidos lógico, físico, y biológico, pero no menos objetivo que ellos puesto que también forma parte del mundo ("Philosophy of Will and Action", 15-16).

Este texto de 1967 también fortalece la idea de una filosofía de la acción distinta de la ética al afirmar que la cuestión del "acto humano", aunque tiene connotaciones éticas no es en sí misma una cuestión ética, sino una investigación previa a la ética (v., op. cit., 9).

A este período pertenecen también otros dos artículos, "Liberté: Responsabilité et decisión" (1968), y "The Problem of the Will and Philosophical Discourse" (1970), en los que, como en "Philosophy of Will and Action", ya es posible encontrar alguna referencia a la filosofía analítica, apuntando en la dirección del desarrollo del curso de 1970-71, posteriormente recogido en El discurso de la acción.

El curso de $1970-71 \mathrm{y}$, por tanto, El discurso de la acción suponen, como ya se ha dicho, la verdadera entrada en escena de la Teoría (analítica) de la acción, cuya presencia, dentro de los márgenes que nos interesan, será casi inevitable en el resto de la obra de Ricoeur. Con ella aparece la noción de red conceptual de la acción, y una transformación en la terminología del autor que le lleva a formular explícitamente la posibilidad de una filosofia de la acción, entendida primeramente como un discurso analítico-descriptivo con una 
doble constitución, analítica y fenomenológica, que da por resultado una "fenomenología lingüística" (EI discurso de la acción, 22 y 24). El papel mediador del lenguaje y la elaboración de un concepto de motivación que vaya más allá de la oposición de causa y motivo se convierten en hitos fundamentales de este período, favoreciendo la articulación (parcialmente iniciada ya en los trabajos sobre Freud y en el artículo de 1967) de la fenomenología con el psicoanálisis, con la filosofía analítica y, a más distancia, con la hermenéutica. Además, las cuestiones que afectan a las relaciones con la ética y con las ciencias humanas, son explícitamente tematizadas (en el mismo sentido, v. "The Problem of the Will and Philosophical Discourse" ${ }^{9}$ ).

\section{Hacia una hermenéutica de la acción}

A partir de este momento (inicio de los años 70) la investigación de Ricoeur sobre la acción se interna definitivamente en la hermenéutica, sirviendo a diferentes objetivos, entre los que destacan el tradicional problema hermenéutico de la dualidad explicar/comprender y la elucidación de las relaciones entre tiempo y narración (junto a otras reflexiones de indole ético- política). Al mismo tiempo que el autor avanza en estos terrenos se va produciendo una relación dialéctica con respecto a los núcleos fundamentales de su concepción de la acción. Sus anteriores conclusiones sobre la motivación, sobre la conexión agente/acción, sobre la estructura acción/pasión o, en otro plano, sobre las funciones del lenguaje y de la interpretación en una filosofia de la acción, contribuyen al desarrollo de las nuevas exploraciones, pero a la vez son reelaboradas en los nuevos contextos recibiendo de ellos otros impulsos.

Las fuentes que alimentan la inflexión hermenéutica de la investigación sobre la acción pueden ser clasificadas en directas e indirectas: las primeras son las que específicamente conciernen a la acción, y las segundas las que remiten a la formación del compromiso hermenéutico de Ricoeur de modo general. En el primer caso se encuentra la analogía entre lenguaje y acción, que a su vez encontramos en dos formas: la textual y la semiótica (v., el epígrafe siguiente). Cabe distinguir en esta categoría influencias heterogéneas, así, en lo que afecta a la consideración de la acción como texto no debe ser ajena la inspiración del pensamiento de J. Nabert ${ }^{10}$, mientras que algunos de los rasgos del análisis de la acción en la estela de Wittgenstein y Austin son utilizados por el autor en beneficio de sus propias expectativas. El examen de la presencia de la acción en la filosofía hermenéutica de Ricoeur debe nutrirse también de otra manera de conectar lenguaje y acción: la relación referencial constituida por la función mimética de la narración, la acción como referencia de la narración.

Por su parte, el índice de la reorientación hermenéutica en el modo general se sitúa preponderantemente en Finitud y Culpabilidad, al enfrentarse al desciframiento del sentido indirecto del lenguaje simbólico. Aún en la perspectiva general ha de ser entendida la controversia que Ricoeur mantuvo con el estructuralismo y que recordaremos más abajo; tanto los las tesis sobre la dicotomía explicar/comprender, como la actitud de Ricoeur ante el problema de la referencia germinan en esa discusión. Entre ambos tipos de fuentes (aunque más próximos al último) pueden ser ubicados los trabajos sobre Freud ya mencionados.

Como organizador de los trayectos a través de las indagaciones sobre explicación y comprensión, y sobre acción y narración, utilizaremos una fórmula ofrecida por el propio Ricoeur en un artículo recogido en Du texte à l'action: la de la doble 
tarea de la hermenéutica. Aunque inicialmente la tarea es definida en relación con el texto trataré de justificar su extensión a la acción. La duplicidad de la tarea se corresponde con la distinción entre sentido y referencia, asi la primera tarea consistirá en "reconstruir la dinámica interna del texto", y la segunda en "restituir la capacidad de la obra para proyectarse al exterior en la representación de un mundo que yo podría habitar"11. A la primera vincula Ricoeur, explícitamente, sus análisis sobre comprensión y explicación, que son situados en un plano preponderantemente epistemológico, y a la segunda sus análisis sobre la referencia (tanto en la metáfora como en la narración), que son colocados en el horizonte de la ontología hermenéutica. El antecedente de ambas tareas puede ser reconocido en el debate que el autor sostuvo con el estructuralismo durante los años 60 , reflejado en gran medida en $L e$ conflit des interprétations.

Veamos ahora cómo se justifica la aplicación de la doble tarea al plano de la acción. Por una parte, el desplazamiento del problema explicar/comprender desde el ámbito del texto al de la acción es llevado a cabo por Ricoeur mediante la analogía entre texto y acción. Pero la cuestión de la referencia es más compleja, ya que la acción es introducida como referencia de cierto tipo de textos (fundamentalmente los narrativos). Por tanto, no cabe aquí una transposición directa como en el caso de la primera tarea: no podemos simplemente pasar de hablar de referencia del texto a hablar de referencia de la acción, sino que, en primer lugar, la acción aparece ella misma como referencia (esta relación referencial entre texto y acción se concretará en la noción de triple mímesis). Sólo después de establecer la analogía texto/acción en el ámbito de la primera tarea se podrá aludir a una referencia de la acción simétrica a la del texto.

\section{Explicación y Comprensión}

Siguiendo el hilo de la primera tarea encontramos una serie de escritos bien representados en la selección de Du texte à l'action, entre estos ocupa un lugar central el artículo "Le modèle du texte: l'action sensée considerée comme un texte" 12 . La utilización del texto como paradigma para la acción abre la posibilidad de considerar la interpretación del texto como modelo para la interpretación de la acción, y constituye uno de los pilares sobre los que se sustenta la posibilidad de una hermenéutica de la acción (en cuyo marco se situarían las ciencias humanas).

Ricoeur ya se había ocupado de la dualidad explicar/comprender al final de $E I$ discurso de la acción, poniendo la concepción de G. H. Von Wright al servicio de la superación de la oposición entre causa y motivo, esa superación se prolonga ahora en el proyecto de una dialéctica entre explicar y comprender.

El mismo año que aparece la edición original francesa de El discurso de la acción, 1977, se publica "La structure symbolique de l'action" ${ }^{13}$, un artículo que resulta bastante útil para aclarar algunos puntos relacionados con la hermenéutica de la acción, en especial la analogía entre texto (lenguaje) y acción según un criterio semiótico ${ }^{14}$. Este trabajo también sirve para hilvanar aún más la transición hacia la segunda de las tareas de la hermenéutica (la que afecta a la capacidad del texto para proyectarse fuera de sí mismo) al abordar en el contexto de la mediación simbólica de la acción, tanto el problema de la interpretación de esta acción, como el de la referencia de la narración. La posibilidad de forjar ficciones de carácter heurístico depende, precisamente, de la capacidad de la narración para redefinir la acción, y ésta, a su vez, se encuadra dentro de la relación referencial que se establece entre el texto 
y la acción. La concepción de la referencia en términos de redescripción proviene de La Metáfora viva, y es un antecedente directo de la noción de refiguración, que ocupará un lugar fundamental en Tiempo y Narración ${ }^{15}$.

\section{La refiguración de la acción}

El desarrollo de la segunda tarea va a suponer el paso desde la noción de referencia a la noción de refiguración a través de la estructura de la triple mímesis antes mencionada. La noción aristotélica de mímesis como representación de la acción es sometida a una expansión que revela tres momentos de la relación entre acción y narración: el de la prefiguración (mímesis-I), el de la configuración (mímesis-II) y el de la refiguración (mímesis-III), de manera tal que "la configuración textual media entre la prefiguración del campo práctico y su refiguración por la recepción de la obra" (Tiempo y narración $I, 118$ ). La formulación de la referencia en términos de refiguración no sólo supone un cambio de vocabulario, sino que implica la subordinación de los aspectos epistemológicos a la dimensión hermenéutica.

En nuestra lectura de la obra de Ricoeur al hilo de las evoluciones de su concepción de la acción observaremos cómo en la noción de mímesis son reelaborados en un nuevo contexto una serie de elementos desarrollados anteriormente. Este es el caso del aspecto simbólico de la acción, de la propia red conceptual de la acción y de la manifestación de la capacidad del texto para ir más allá de sí mismo mediante la incidencia de la narración en el mundo de la acción; junto a ellos aparecen ahora 'los rasgos temporales de la acción.

La cuarta parte de Tiempo y Narración (volumen III) gravita en torno al tercer momento de la mímesis: la refiguración que la narración ejerce sobre el orden de la acción. centrándose sobre todo en su dimensión temporal. Nuestro interés debe focalizarse aquí sobre tres planos: (1) el papel fundamental de la praxis en la réplica poética a las aporías de la fenomenología de la temporalidad, y la propuesta de la noción, eminentemente práctica, de iniciativa, (2) la refiguración ejercida sobre el mundo del lector, y (3) la aproximación a una hermenéutica de la conciencia histórica, que afianza algunos de los rasgos que caracterizan la manera en que Ricoeur concibe la acción.

A pesar de que la distinción de una doble tarea de la hermenéutica muestra unos contornos bastante nítidos en su proyecto, la separación entre las dos tareas no es, en la práctica, completa. Por ejemplo, la referencia ocupa un lugar importante también en la primera tarea, donde el autor llega a hablar, como ya mencioné, de referencia de la acción misma. Por otro lado, el fenómeno de la interpretación tenderá un profundo puente entre ambas tareas en virtud de su conexión con la noción de comprensión, de un lado, y con la noción de refiguración, de otro. Al mismo tiempo que la cuestión de la referencia supone la implicación de aspectos ontológicos en la primera tarea, es posible advertir en la segunda la presencia, aunque subordinada, de aspectos epistemológicos.

El concepto de identidad narrativa, que surge en Tiempo y Narración como un efecto de la refiguración, puede ser tomado como guía de la siguiente transición, en esta senda brevemente esbozada, por su contribución al reto suscitado por la pregunta sobre el quién de la acción.

\section{La filosofía de la acción como reapropiación de sí}

Y llegamos, finalmente, a Sí mismo como otro, cuya unidad temática (en un sentido analógico) la proporciona el actuar huma- 
no. En esta obra se recogen materiales anteriormente desarrollados a partir de las aproximación fenomenológica y de su contacto con la filosofía (analítica) de la acción, así como los derivados del paso por la doble tarea hermenéutica. Pero estas aportaciones, son una vez más objeto de una organización conjunta enriquecida con nuevas perspectivas, la reflexión sobre la acción contenida en Sí mismo como otro puede ser entendida como un auténtico detour en la vía larga de la autocomprensión. Desde el punto de vista de la secuencia de los diferentes estudios la obra supone una extensión y una concreción progresivas de la noción de acción; a su vez, esta secuencia se estructura en cuatro partes que se corresponden con la descomposición de la pregunta ¿quién? ?6 $^{16}$ en otros tantos interrogantes: ¿quién habla?, ¿quién actúa?, ¿quién se cuenta -o se narra-?, y ¿quién es el sujeto moral de imputación?. La incorporación de la dimensión ética se produce también en otro principio organizador: el ritmo ternario describir, relatar, prescribir, en el cual podemos apreciar la relación entre teoría de la acción, teoría narrativa y teoría ético-política que ya había sido indicada en Du texte à l'action. Aunque este principio ternario responde a la distribución de los estudios que componen la obra (con excepción del último), puede ser leído en cualquier otro orden: en realidad ninguna de las tres aproximaciones es, según Ricoeur, primera en todos los sentidos.

A la organización ternaria (describir, relatar, prescribir) hay que añadir la perspectiva ontológica aportada por el estudio final, pero también en él el actuar humano ocupa un lugar privilegiado, entendido como "un modo de serfundamental" al que el autor se acerca mediante una estructura que reproduce una constante procedente de los análisis de Le volontaire et l'involontaire: la estructura acción/pasión.

La reelaboración de los materiales precedentes, a los que he aludido más arriba, continúa en Sí mismo como otro sobre todo con respecto a la relación agente/acción y a la estructura acción/pasión; también la oposición entre causa y motivo, con la distinción paralela entre movimiento y acción, se complica con nuevos argumentos, como los de D. Davidson. Lo mismo cabe decir de las cuestiones que afectan al estatuto epistemológico de una filosofía de la acción, entre las que destaca la articulación del discurso descriptivo con el prescriptivo. Y todo ello bajo el signo de la pregunta ¿quién?, cuya respuesta apunta a una concepción hermenéutica del sujeto (o más exactamente a la transformación hermenéutica de la vieja noción de sujeto): al "sí-mismo", al soi.

\section{IDENTIFICACIÓN DE UNA FILOSOFÍA DE LA ACCIÓN EN P. RICOEUR}

\section{Sobre la existencia de una filosofia de la acción}

\subsection{Autonomía y contornos}

Por lo que afecta a la distinción entre filosofía de la acción y ética, podemos encontrar diferentes ocasiones, algunas ya se han señalado, en las que Ricoeur distingue entre ciertas aproximaciones filosóficas a la acción y un plano ético; incluso existe, al menos, una distinción expresa entre filosofía de la acción y ética en $E l$ discurso de la acción $n^{17}$. Por otro lado, nuestro autor ha buscado, también en varios lugares, la articulación entre un discurso descriptivo, analítico, o científico-interpretativo, de la acción y un discurso ético (que, en ocasiones, incorpora la dimensión política), o en términos generales, entre descripción y prescripción. Esto es lo importante: la constatación, tanto de la diferencia entre los dos tipos de discurso, como de los intentos de articulación de ambos planos. En principio, el uso de la 
expresión filosofia de la acción en un sentido específico restringido parece estar justificado, si bien nada impide que, siempre que se distinga claramente uno de otro, se pueda utilizar en un sentido amplio que albergue también su pensamiento ético $(y$ probablemente, sus aportaciones a la filosofía política y del derecho). Por un lado, la diferencia (tematizada o simplemente de hecho) entre los dos tipos de aproximaciones o discursos justifica que podamos hablar de una filosofia de la acción diversa de la ética en Ricoeur, por otro lado, la continuidad entre ambas, y la forma en que la segunda se sostiene sobre la primera, autorizarian a hablar de una filosofia de la acción que incluyera el conjunto de las ideas de Ricoeur sobre la acción en su totalidad ${ }^{18}$. En el primer caso (filosofía de la acción en sentido restringido), la acción es afrontada en un plano, frecuentemente antropológico y epistemológico (a veces ontológico), en el que aún no ha sido cualificada ética, política o juridicamente. Como se desprende de lo ya dicho el uso relevante para nosotros es el restringido, que es el que pretendo elucidar aquí.

\subsection{Cohesión y diversidad}

La noción de una filosofía de la acción plantea también la cuestión de la dispersión y la heterogeneidad de las investigaciones de Ricoeur en torno a la acción. En este punto lo que interesa es determinar el grado de heterogeneidad, dilucidar si esa heterogeneidad es asumida en una evolución coherente, o si existen elementos comunes a las distintos acercamientos a la acción (en el sentido restringido), y en tal caso saber cuales son y cuál es su relevancia. En cualquier caso, la noción de filosofía de la acción nunca puede ser atribuida al filósofo francés en un modo sistemático (contrastando, desde esta perspectiva, con el proyecto - y sólo en tanto que proyecto- de una Filosofia de la Voluntad expresado en Le volontaire et l'involontaire).

Trataré esta cuestión en dos fases. En la primera fase señalo cómo distintas aproximaciones al mundo de la acción van integrándose progresivamente en una fórmula característicamente ricoeuriana (aunque no exclusiva). En la segunda, plantearé el problema desde la perspectiva de la polisemia de la acción, considerando el uso del concepto de acción.

1.2.1. La formación de la filosofia de la acción como integración de distintos estratos

Hemos apuntado cómo se pueden seguir las evoluciones de una filosofía de la acción en Ricoeur partiendo de Le volontaire et l'involontaire, donde tal denominación no se reduce a la teoría de la acción desarrollada en la segunda parte del libro, sino que, según el criterio de la red conceptual de la acción, abarca el conjunto de la obra. En esta primera fase esa filosofía de la acción se caracteriza, desde el punto de vista metodológico, por responder al modelo de la descripción fenomenológica y por hacer abstracción de la dimensión ética. El estrato fenomenológico ha contribuido a la filosofía de la acción de Ricoeur con algunos de sus elementos fundamentales: la estructura acción/pasión (no hay actividad sin pasividad), la noción de poder (y su vinculación a lo posible), la doble valencia del cuerpo como cuerpo propio o cuerpo- objeto, la fidelidad (progresivamente matizada) a la perspectiva de la primera persona, es decir, del agente, etc.

La transformación de esta primera fórmula (la de Le volontaire et l'involontaire) ${ }^{19}$ contiene dos vectores, uno directo y otro indirecto, el primero es el que conduce, a través del encuentro con la filosofía analítica, a la noción propuesta en el curso de 1970- 71 sobre la semántica de la acción (posteriormente recogida en El discurso de la acción). Ese es el lugar por excelencia 
de la tematización del concepto de filosofía de la acción en Ricoeur, donde, en principio, se limita al discurso analítico/descriptivo de la acción surgido del encuentro de la fenomenología con el análisis del lenguaje. El estrato analítico incorpora la mediación del lenguaje como modo de escapar al cortocircuito de la autoconciencia fenomenológica, Ricoeur propone acceder a la fenomenología a través del análisis lingüistico porque ese punto de partida tiene la ventaja de no poner inmediatamente en juego la intuición privada sino el enunciado público de la acción. En esta formulación la filosofía de la acción se distingue tanto de la ética como de las ciencias de la acción, pero implícitamente su alcance va más allá y considero que puede ser ampliado hasta abarcar no sólo un discurso sobre la acción, sino también un discurso (de segundo grado) sobre el discurso de la acción, es decir, hasta incluir las reflexiones y teorías en las que el discurso (filosofía de la acción) no se ocupa directamente de la acción, sino que se dirige a sí mismo para analizar sus relaciones con la ética y con las ciencias humanas. La filosofía de la acción es, entonces, también una filosofía sobre el discurso, o los discursos, de la acción (v. El discurso de la acción, capítulos I y V).

El segundo vector de la transformación pasa por el "giro hermenéutico" del pensamiento de Ricoeur, y presenta, a su vez dos facetas, aunque ambas comparten como rasgo sobresaliente la presencia del texto. Una, que tiene su eje en la discusión sobre la explicación y la comprensión de la acción, es la que incorpora distintas reflexiones y propuestas en torno a las ciencias humanas utilizando como modelo la hermenéutica textual. La otra es la que pone en juego las relaciones entre acción y narración, atravesando la trilogía Tiempo y Narración sobre la base de su conexión mimética. A grandes rasgos estas dos facetas coinciden con las dos tareas de la hermenéutica señaladas más arriba.
Tenemos asi una acumulación de estratos que, lejos de yuxtaponerse, interactúan positiva y dinámicamente. Este proceso va conformando una filosofía de la acción que se caracteriza por la conjugación de fenomenología, análisis lingüistico y hermenéutica (con sus diversas conexiones con las ciencias humanas y con la teoría narrativa). De esta manera comenzamos a responder, desde un punto de vista metodológico y epistemológico, a la pregunta por la naturaleza de una eventual filosofía de la acción en Ricoeur. La afirmación del propio autor de que la teoría de la acción necesita para asegurar su autonomía una "nueva alianza entre la tradición analítica y la tradición fenomenológica y hermenéutica" (Sí mismo como otro, 106) debería ser interpretada a la luz de esta conclusión. La articulación de las tres tradiciones no sólo se produce en Sí mismo como otro, sino que se halla en El discurso de la acción (aunque de forma incipiente en lo que respecta a la hermenéutica), en "La structure symbolique de l'action", y más claramente en distintos artículos de Du texte à l'action, especialmente en la segunda parte, como en los que se dirime la distinción entre causa y motivo, y su correspondencia con la dualidad explicar/comprender, o en el dedicado a la noción de iniciativa, que converge con algunos análisis de Tiempo y Narración (v., capítulo 7 del tercer volumen). La elaboración de este último concepto constituye uno de los paradigmas de la combinación de recursos fenomenológicos, analíticos, y hermenéuticos en la meditación ricoeuriana sobre la acción ${ }^{20}$. También resulta ejemplar la constitución de la mimesis, especialmente de mímesis- I (momento de la prefiguración de la acción), en el capítulo III de Tiempo y Narración $I$

\subsubsection{La polisemia de la acción}

La discusión acerca de la unidad/heterogeneidad de las distintas aproximaciones 
de Ricoeur al tema de la acción debe pasar también por la consideración de los diferentes usos del término "acción" a lo largo de su obra. Realmente hay una polisemia de hecho antes de que el autor reflexione explícitamente sobre ella. A partir del uso que Ricoeur hace del término podemos distinguir, fundamentalmente, tres conceptos de acción, a los que posteriormente añadiremos el de Max Weber:

(A) En primer lugar, el determinado por las nociones de moción voluntaria y pragma. El término pragma designa el correlato intencional del actuar, lo que es hecho, y no sólo comprende un conjunto de movimientos, sino también un conjunto de relaciones efectuadas al actuar. En el contexto fenomenológico en el que comienza a desarrollarse el proyecto de una filosofía de la voluntad, la acción aparece estrechamente ligada al concepto práctico de poder (poder-hacer) y es, fundamentalmente, entendida como movimiento corporal voluntario que produce cambios en el mundo (v. Le volontaire et l'involontaire, 193-197). Este es el significado predominante en Le volontaire et l'involontaire, aunque también podemos encontrar otros usos secundarios o subordinados, como ocurre cuando la motivación y el pensamiento son contemplados bajo el modelo de la acción: el concepto de acción se extiende, entonces, más allá del estricto movimiento corporal efectivo, o cuando se utilizan expresiones como "acción involuntaria". Por otra parte, el autor emplea, a veces, de forma intercambiable vocablos como "acción", "acto", "conducta", "comportamiento", e incluso en alguna ocasión utiliza los términos "acción" y "acontecimiento" como sinónimos (v. Le : volontaire et l'involontaire, 191).

(B) El segundo concepto de acción es el de la Teoría de la acción (la corriente surgida en el contexto de la filosofía analítica), especialmente en la versión representada por E. Anscombe ${ }^{21}$. Este signifi- cado entra en la obra de Ricoeur fundamentalmente a partir del curso de 1970-71 sobre la semántica de la acción, pero será usado sin distinguirlo de otros hasta Sí mismo como otro (v., especialmente, op. cit., 152-166). Este concepto se puede caracterizar por su dependencia del análisis lingüístico (y más ampliamente de la concepción analítica de la filosofía), por limitarse a segmentos de acción expresados en frases de acción, y por abstraer tales segmentos de su contexto social. Además, la distinción entre acción y acontecimiento, y entre motivo y causa, contribuye, junto a la idea de la red conceptual de la acción, a fijar el presente significado.

El problema surge cuando el autor mezcla este uso con otros, por ejemplo, en Mimesis I podemos presumir que el concepto de acción utilizado para presentar los rasgos estructurales de la acción es el de la Teoría de la acción, puesto que emplea su vocabulario y sus recursos (v. Tiempo y Narración I, 120-123), sin embargo, el concepto de acción en el que se basa la propia noción de mímesis, como instrumento privilegiado para afrontar la relación entre acción y narración, es un concepto explícitamente vinculado al significado de la "praxis" en Aristóteles (queda claro en los capítulos II y III de Tiempo y Narración I, v., por ejemplo, 83- 94). La polisemia latente en estos usos puede confundir al lector e introduce en la argumentación un factor de imprecisión conceptual.

(C) Este último significado (el relacionado con la noción de mímesis) es el que ahora deseo subrayar, un significado que acompaña toda la reflexión del autor sobre las relaciones entre acción y narración. Uno de los usos más desconcertantes del concepto de acción se encuentra a propósito de tales relaciones, cuando el arco prefiguración/configuración/refiguración es introducido para expresar la relación entre acción y narración, designada por la noción de triple mímesis. Encontramos que 
el lugar final del proceso, el objeto de la refiguración, es ocupado por distintos términos en distintas ocasiones, la narración refigura la acción, pero también refigura el tiempo, y en otro momento refigura el mundo del lector, y por si no era suficiente refigura (sobre todo en Sí mismo como otro) la vida. Aunque Ricoeur no se preocupa por justificar estas variaciones terminológicas ha diseminado datos suficientes para comprender, en una primera aproximación, al menos el uso de los tres primeros elementos: por una parte, el tiempo es en Tiempo y Narración la dimensión fundamental del mundo de la acción, por otra, ambos, tiempo y acción, son refigurados a través de la lectura. Si bien el problema dista de estar completamente resuelto en cuanto a la sustitución de la acción por el tiempo y por el mundo del lector como destinos de la refiguración, no resulta, asi, tan apremiante como el que plantea la distancia entre decir "acción" y decir "vida".

La primera hipótesis para explicar este uso del vocabulario nos lleva necesariamente a suponer que para Ricoeur existe algún tipo de imbricación semántica entre las expresiones mencionadas, y que el concepto de acción no puede tener el limitado alcance que tenía en los dos casos anteriores (A) y (B). Si el mundo sobre el que opera la refiguración es el mundo del lector, es legítimo deducir de la utilización de estos términos por parte de Ricoeur que, en algún sentido, tal mundo es la vida, y que la vida es fundamentalmente entendida por el autor desde la óptima de la acción. Esta conclusión se confirma y se precisa en una de las contadísimas ocasiones en las que Ricoeur menciona esta cuestión, al afirmar que la mezcla del hacer y el padecer (designada por la estructura acción/pasión) constituye "la verdadera textura de la vida", a la cual se dirige la mímesis de la ficción (v. "Life: A Story in Search of a Narrator", A Ricoeur Reader:
Reflection and Imagination, 43222). Podemos observar aquí cómo se establece una relación esencial entre la acción (entendida como mezcla de actividad y pasividad), la vida, y aquello que es prefigurado y refigurado por la mímesis.

Pero ya iniciada esta indagación, la noción de refiguración nos impulsa a seguir cuestionándonos sobre el significado de esa "textura de la vida", y sobre la naturaleza de esa vida que no se reduce a un mero fenómeno biológico (la vida sólo deja de serlo si es interpretada - ibíd.-). Pues bien, hemos visto que la idea de refiguración surgió de la evolución del concepto de referencia del texto literario que comenzó a forjarse en La metáfora viva. Esta referencia propia de la literatura nos muestra su cariz ontológico al establecer una relación entre el texto y la realidad extralingüistica, pero ¿en qué consiste esta realidad que es el mundo de la referencia literaria?. No es el mundo de la referencia del lenguaje descriptivo o científico, sino que se sitúa en el mismo plano que las nociones de mundo de la vida (Husserl) y ser-en-el-mundo (Heidegger). Cuando la ficción regresa al mundo en términos de refiguración, y ese mundo al que regresa es el mundo del lector, y a través de éste refigura la textura (acción/pasión) de la vida, la vida, la acción, el mundo, comienzan a formar el índice de una concepción de la realidad como mundo de la acción, en la cual el concepto de acción alcanza una significación ontológica. En una revisión global del conjunto de su obra Ricoeur ha vuelto a asumir que los enunciados metafóricos y narrativos tienden a refigurar lo real por mediación de la lectura, y que tal refiguración constituye "una activa reorganización de nuestro ser- en- el- mundo" (Autobiografía intelectual, 76) ${ }^{23}$. En esa misma obra encontramos una afirmación que, en conexión con la anterior, nos permite afianzar lo que nuestra exploración del concepto de acción en 
la terminología de la refiguración nos sugería: "el actuar constituye, en una filosofía aprehendida cada vez más como filosofía práctica, el nudo de lo que, en la ontología heideggeriana y post-heideggeriana, es llamado ser-en-el-mundo, o, de manera más aprehensiva, acto de habitar (habiter) ${ }^{24 "}$ (Autobiografía intelectual, 62-63).

Creo que ahora podemos apreciar mejor este tercer concepto de acción, y resulta más fácil entender la inestabilidad que nos sorprendió en el vocabulario de la refiguración y de la mímesis.

$\mathrm{Al}$ análisis de los tres conceptos de acción que acabamos de realizar hay que añadir algunas precisiones para completar, al menos en sus rasgos fundamentales, nuestras conclusiones sobre los distintos usos del término en Ricoeur.

Por su propia riqueza y complejidad, y quizás por un uso no lo suficientemente cuidado, el concepto de acción suscita también otros problemas. Un caso digno de ser considerado es aquel en el que el modelo de la dialéctica entre explicación y comprensión, mediante la cual el autor pretende superar los planteamientos dicotómicos, es aplicado a los fenómenos sociales. En el conjunto de la argumentación aparecen, al menos, tres versiones del concepto de acción, una de ellas es la de Max Weber, presentada como vehículo para aplicar el paradigma del texto a la acción, en tanto que objeto de las ciencias humanas (v. Du texte à l'action, 190). Sin embargo, la noción weberiana de acción no acaba de mantenerse pacíficamente en ese contexto, como lo muestra la introducción poco convincente de los fenómenos sociales en la dialéctica explicar/comprender (v., op. cit., 205-211). Lo que falta en la argumentación de Ricoeur es precisamente la transición desde la mera acción a los fenómenos sociales: sin esa justificación la introducción de tales fenómenos en la dialéctica explicar/comprender resulta más bien forzada.
Aunque es posible comprender el tránsito de la acción a los fenómenos sociales acudiendo al encuentro de las concepciones sociológicas (Weber), antropológicas (Geertz) y analíticas de la acción en "La structure symbolique de l'action" ${ }^{25}$, no encontraremos una tematización explícita satisfactoria hasta Si mismo como otro: pienso, en primer lugar, en el proceso de expansión del campo práctico que parte de la noción de acción en la Teoría de la acción y conduce hasta un concepto tan amplio como el del tipo (C), más arriba considerado (próximo a la "praxis" aristotélica y desarrollado a partir de la concepción de la unidad narrativa de la vida de A. MacIntyre). En este proceso, la definición de acción social de Weber se incorpora con soltura, en el nivel de las prácticas, a la expansión aplicada al concepto de la Teoría de la acción (v. Sí mismo como otro, 152-166).

Por otra parte, los diferentes estudios de Sí mismo como otro responden a un planteamiento fragmentario que es mitigado por tener al actuar humano como unidad temática. Ricoeur hace corresponder este carácter fragmentario con el fenómeno de la polisemia de la acción, presentando la unidad temática como una unidad "solamente analógica entre las múltiples acepciones del término actuar" (op. cit., XXXIII). En este contexto, el autor viene a distinguir varios sentidos del actuar humano que pueden ser organizados en función del trio describir/narrar/prescribir, cuyo orden únicamente tiene una función didáctica tendente a guiar al lector "en la travesía de la polisemia del actuar" (ibíd.). Desde este punto de vista, dos de los conceptos de acción que examinamos más arriba, (A) y (B), caerían dentro del primer elemento de la triada: describir, mientras que el concepto (C) perteneceria, ahora, al segundo elemento: narrar. Quedaría, por tanto, un tercer sentido, el del prescribir, que también formaria parte de la 
polisemia de la acción. Este último sentido define el marco de la esfera ético-política que nosotros hemos dejado fuera o, más precisamente, en las lindes de nuestra indagación.

En resumen, por un lado, las distintas aproximaciones de Ricoeur al campo de la acción humana, en el sentido restringido que nos interesa, se integran en una evolución coherente que desemboca en la fórmula de una filosofía de la acción mediante la articulación de fenomenología, análisis lingüístico y hermenéutica. No se trata, claro está, de una articulación completa o sistemática, sino de la utilización conjunta de recursos y materiales procedentes de tres tradiciones que no siempre son compatibles. Por otra parte, una polisemia de la acción, de hecho y de derecho, se constituye en unos de los rasgos de esa filosofía de la acción. Pero la fragmentariedad implicada por esta polisemia debe ser complementada, no sólo con la ligazón ofrecida por una unidad analógica como la propuesta en Sí mismo como otro, o con la organización conceptual ofrecida por la expansión del concepto de acción y por la tríada describir/narrar/prescribir, sino, sobre todo, con la permanencia profunda de ciertos elementos claves en el contenido de la concepción básica de la acción en nuestro autor. Veamos, a continuación, cuales son esos elementos.

\section{Tres constantes dinámicas}

La concepción de la acción de Ricoeur presenta una serie de rasgos fundamentales que, de una manera dinámica, permanecen a lo largo de toda su obra, aunque bajo diversás luces y alimentando distintos objetivos. Si, de un lado, la polisemia de la acción es, en sus diferentes versiones, un hecho incontestable, de otro lado, cabe determinar un núcleo, esencial y complejo, que señala un modo particular de entender la acción humana. En mi opinión, la clave de la constitución de la filosofía de la acción en Ricoeur es precisamente el juego entre la diversidad representada por la polisemia de la acción y la constancia proporcionada por tales rasgos.

\subsection{Acción y pasión}

En Ricoeur no hay acción sin pasión (o receptividad, como se dice en Le volontaire et l'involontaire), una no va sin la otra, hasta el punto de que donde he hablado de filosofía de la acción podría haber dicho, quizás con más exactitud, filosofia de la acción y de la pasión. Esta adherencia se halla explícitamente acentuada en las dos obras que constituyen los extremos del recorrido (la senda de la acción) propuesto más arriba.

La propia acción es el resultado de una combinación de actividad y pasividad, pasividad que no sólo depende de circunstancias exteriores, sino que anida en el interior del sujeto, o mejor, del agente. La estructura acción/pasión está presente en todas las aproximaciones del autor al tema de la acción (aunque, en ocasiones, de modo implícito). Constantemente encontramos la convicción de que la combinación de actividad y pasividad determina la naturaleza del actuar humano. Esa misma combinación delimita el ámbito de lo posible, de la acción posible, para un sujeto hecho de esa misma mezcla y confrontado a un mundo que es, a su vez, límite y ocasión. Pero la estructura acción/pasión nos revela también que el mundo, desde el punto de vista práctico, es un mundo de agentes y pacientes, toda acción es, en este sentido, interacción, y todos somos simultánea o alternativamente agentes y pacientes. El poder, la violencia, y la justicia son figuras de la interacción, pues mientras que las primeras designan relaciones asimétricas en las que el paciente puede llegar a convertirse en víctima, la justicia trata de restablecer la igualdad entre agentes y pacientes ${ }^{26}$. 
El pensamiento de Ricoeur sobre nuestra condición histórica también está guiado por la estructura acción/pasión. La elaboración de una hermenéutica de la conciencia histórica es entendida como "una interpretación de la relación que la narración histórica y la narración de ficción mantienen, conjuntamente, con la pertenencia de cada uno de nosotros, en tanto que agentes y pacientes, a la historia efectiva" (Temps et récit III, 186) ${ }^{27}$

\subsection{Acción y sujeto/agente}

"La emergencia de la voluntad como problema filosófico expresa la progresiva emergencia de la subjetividad como modo de ser predominante", escribía Ricoeur en 1970 ("The Problem of the Will and Philosophical Discourse", 285). Esta es una de las muchas formas en las que la subjetividad aparece implicada en la red conceptual de la acción (a la que también pertenece la voluntad).

Las relaciones entre la acción (acción/pasión) y el sujeto dan lugar a otro de los núcleos más poderosos en el área de pensamiento que fundamentalmente nos interesa de nuestro filósofo. En ella el sujeto es, sobre todo, entendido como agente (agente/paciente), lo que envuelve no pocas complicaciones, al establecer una urdimbre de ramificaciones que comunican nociones como las de identidad (y por tanto, identidad narrativa), iniciativa, poder (poder-hacer), responsabilidad ${ }^{28}$, causa y motivo, hasta entrar en la esfera de la ontología, ya apuntada en la cita anterior ("modo de ser" - mode of being-), y cuya presencia más deliberada la hallaremos en Sí mismo como otro. La constitución conceptual de todos estos elementós reenvía al núcleo anterior ya que está regida por la estructura acción/pasión.

La cuestión del sujeto genera, además, una de las fuentes que introducen la - dimensión hermenéutica en la filosofía de la acción, especialmente a partir de los tex- tos sobre Freud, donde se afirma el fracaso de la conciencia inmediata y la necesidad de una mediación/interpretación en la reflexión. A partir de ahí el autor utilizará expresiones como "cogito herido" o "mentira de la conciencia" para referirse a ese fracaso, y la autocomprensiớn será siempre entendida en términos hermenéuticos: "No hay comprensión de sí que no sea mediatizada por signos, símbolos, y textos: la comprensión de sí coincide en última instancia con la interpretación aplicada a estos términos mediadores", escribirá en un artículo de 1989 recogido en $D u$ texte à l'action (op. cit., 29). Esta convicción conducirá finalmente a la elaboración de una hermenéutica de sí- mismo (del soí) en Sí mismo como otro; pero la comprensión de sí también pasa por la comprensión y la interpretación de la acción (que muestra, entonces, su dimensión simbólica), especialmente cuando ese "sí" es concebido como agente.

Cabe iluminar el problema de la causa y el motivo con éste mismo foco en tanto que se trate de elucidar si el agente es causa de sus acciones. La distinción entre el acontecimiento y el mero movimiento físico, de un lado, y la acción humana, de otro, añade otra faceta a la misma investigación. Tal indagación termina también por conducir hacia la cuestión del determinismo, en tanto que la noción de causa ha expresado con frecuencia en el pensamiento moderno las relaciones entre fenómenos naturales.

Otro aspecto relevante en este punto es el suscitado por la noción de poder- hacer. Se trata de un elemento decisivo en la concepción de la acción de Ricoeur, la afirmación de nuestro poder- hacer, de nuestra capacidad para actuar, y la conceptualización de este fenómeno han ocupado un lugar capital en muchas de las meditaciones del autor sobre la acción, pero aunque no fuera tematizado, ni explícitamente afirmado, su presencia (implí- 
cita o subyacente) es otra de las constantes que debemos reconocer. Sus enlaces con el conjunto de la red conceptual de la acción se hacen evidentes por lo que respecta al problema causa/motivo, ya que una de las funciones de la noción de poder-hacer es la de explicar la eficacia del agente en la realización de acciones y la dependencia de tales acciones con respecto a su agente (cuestiones estas que, además, involucran el correlato de la pasividad, ya que tal eficacia y tal dependencia se ubican dentro de la estructura general acción/pasión).

Por otro lado, la idea de una cierta constitución mutua del agente y su acción, desarrollada en los estudios sobre la narración, estaba ya en Le volontaire et l'involontair $^{29}$. Junto a la estructura acción/pasión, la conexión entre el agente y su acción sirve también al autor como perspectiva privilegiada para afrontar una concepción del sujeto, de alcance antropológico y ontológico, a partir de la pregunta por el quién de la acción: un sujeto capaz de entrelazar sus intenciones con los acontecimientos del mundo, un ser que pertenece a la vez al régimen de la causalidad y al de la motivación, que debe ser comprendido pero también explicado. En otro plano, en el que deliberadamente nos hemos detenido, la noción de ese sujeto capaz forma parte de una filosofía de la acción que proporciona las bases sobre las que elaborar una ética de la persona o un argumento sobre el sujeto del derecho ${ }^{30}$.

\subsection{La pasión por lo posible $e^{31}$}

A pesar de que esta expresión es utilizada por el propio Ricoeur literalmente propondré un contenido y un uso distintos de los ofrecidos por el autor. Un uso y un contenido distintos pero no incompatibles, sino más bien complementarios.

Esta expresión, con la que explícitamente alude a Kierkegaard, aparece en Ricoeur como manifestación de "la liber- tad según la esperanza": "Sị se quiere expresar en términos psicológicos apropiados la libertad según la esperanza, habrá que hablar, con Kierkegaard, de la pasión por lo posible, que retiene en su fórmula la marca de futuro que la promesa pone sobre la libertad" (Le conflit des interprétations, 398) ${ }^{32}$. El significado de la pasión por lo posible se hace patente por contraste con el primado de la necesidad en una "ética del presente" que Ricoeur encuentra en Parménides, en los estoicos, en Spinoza, y por otra parte, en el "amor fati" de Nietzsche y en el principio de realidad de Freud (v., op. cit., 398- 399). La pasión por lo posible que, por un lado, se encuentra en el polo opuesto de ese primado de la necesidad, está, por otro, alineada junto a la imaginación, a una imaginación creadora que, psicológicamente, representa la fuente de lo posible (v., op. cit., 399).

De esta concepción, que ya de partida no recoge las decisivas implicaciones que tiene en Kierkegaard con respecto a la angustia y a la desesperación, retendremos su determinación con respecto al primado de la necesidad y su vínculo con la imaginación. Por otro lado, haremos abstracción de las connotaciones religiosas y lo circunscribiremos al campo de la acción, entendiendo el tema de lo posible desde la perspectiva de la prioridad que en Ricoeur tiene lo práctico sobre lo teórico/representativo. Además, debemos tener en cuenta otros usos que el autor hace del concepto de 10 posible en el conjunto de su obra. La nueva configuración de la pasión de lo posible a la que así accedemos designa el tercer núcleo de su filosofía de la acción.

Con la pasión por lo posible quiero aludir a una cuestión previa (en determinado sentido) a la pregunta "¿qué hacer?", o si se prefiere, a una versión específicamente ética de la misma como "¿qué debo hacer?". A tal cuestión previa apunta otra clase de preguntas, preguntas del tipo "¿qué puedo 
hacer?", cuya respuesta implica despejar otros interrogantes: por ejemplo, si es posible hacer algo (en un sentido específicamente humano) y cómo es posible ese hacer (e incluso, qué puedo querer).

Este tipo de preguntas exploran en Ricoeur la zona media, el "terreno intermedio" en el que, en mi opinión, debe moverse hoy la filosofía. Tal "terreno" es intermedio con respecto a diferentes hitos o mojones: podríamos identificar como tales, por un lado la ambición de fundamentación última del cogito, y por otro, la crítica de Nietzsche, según aparecen descritas en el Prefacio de Sí mismo como otro. Ricoeur, por su parte, prefiere situarse más allá de la alternativa cogito/anti- $\mathrm{CO}$ gito (op. cit., XXVIII-XXIX); en realidad, ese "más allá" no es distinto de lo que pretendo designar con la expresión zona media. Otros de esos mojones extremos serian, por ejemplo, el dogmatismo y el escepticismo radical, la fundamentación última y la arbitrariedad, o los señalados por la tesis y la antítesis de la tercera antinomia kantiana. En Ricoeur la exploración recorre diferentes regiones, pero nosotros nos limitaremos a un sector de ese ámbito intermedio, el que más directamente concierte a la acción: entre una libertad ideal y la necesidad absoluta, entre la ausencia de motivos y la mera causalidad física, entre el poder de un sujeto completamente dueño de sí y de sus acciones, y la incapacidad de un sujeto aniquilado o exangüe, entre las pretensiones de un Saber Absoluto y la deriva del sin sentido.

La búsqueda de lo posible se juega en ese "terreno intermedio", conjugando la acción y la pasión, la razón con el deseo, y desvelando la vinculación del agente con sus acciones. Ahí se responde a preguntas del tipo "¿qué puedo hacer, si es que puedo hacer algo, y cómo es posible ese hacer?". Ciertamente "Querer no es crear" ( $L e$ volontaire et l'involontaire, 456), pero puedo actuar, puedo intervenir, puedo ser un sujeto responsable, el tema de lo posible nos da entonces la llave para entender las otras dos constantes dinámicas. la estructura acción/pasión y la conexión acción/agente. Las indagaciones, una y otra vez retomadas, sobre las nociones de causa y motivo, y sobre el concepto de poder (como poder-hacer o poder activo), trabajan de manera destacada a favor de la pasión por lo posible. En términos semejantes cabe interpretar la articulación de lo voluntario con lo involuntario, la concepción del mundo como mundo de la acción o, por supuesto, la noción de iniciativa ${ }^{33}$, pero aún hay otro aspecto que sirve al mismo impulso, y que ya he mencionado más arriba: el de la imaginación creadora. La imaginación establece un nexo entre acción y ficción que Ricoeur concibe bajo la idea de la imaginación como "función general de lo posible práctico" (Du texte à l'action, 225) ${ }^{34}$.

La perspectiva de lo posible expresa también la doble valencia que la cuestión de los límites tiene en la filosofía kantiana ${ }^{35}$, en el sentido de que la afirmación de una capacidad va inevitablemente unida a la determinación de sus límites. En nuestro caso, esa capacidad sería la de actuar. Capacidad que es designada precisamente por la noción de poder-hacer, capacidad que, además, forma parte integrante de la respuesta de Ricoeur al problema causa/motivo, y que manifiesta a la perfección la estructura acción/pasión del mundo de la acción ${ }^{36}$. El ámbito de lo posible viene marcado por sus dos vertientes: una positiva, otra negativa. En el aspecto positivo lo posible indica apertura de horizontes, exploración del espacio de lo inédito, en el aspecto negativo señala sus propios limites, los límites de lo posible. Gracias a este doble valor la categoría de lo posible puede conjugar las nociones de creación y de finitud, que separadas y maximizadas (elevadas al rango de absolutos) determinan los extremos de un territorio filosófico intermedio, de una zona media, que es el lugar 
natural de lo posible. La estructura acción/pasión es el índice analítico de una visión del mundo en la que la finitud y la creación no se excluyen y en la que la apuesta por lo posible permite pensar tanto el sujeto capaz, del que hablábamos más arriba, como la posibilidad misma de la acción histórica en un contexto post-hegeliano.

Pero el tema de lo posible supera en Ricoeur los contornos del cuadro que acabo de esbozar, pues penetra en su concepción de la imaginación y en sus exploraciones ontológicas y escatológicas ${ }^{37}$.

La dimensión creadora de la imaginación ha sido proyectada sobre la esfera de la acción de varios modos. Así ocurre cuando la teoría de la imaginación centrada sobre la noción de innovación semántica es extendida hasta la esfera práctica en "L'imagination dans le discours et dans l'action" (recogido en Du texte à l'action, 213-236). Este proceso es entendido por el propio autor como un momento dentro del desarrollo de una Poética de la Voluntad (ibíd.) (que constituía la tercera fase nunca escrita como tal ${ }^{38}$, de su proyectada Filosofia de la Voluntad). La imaginación descubre nuevas posibilidades para la acción, posibilidades que son ensayadas y probadas en el mundo de la ficción. En la imaginación tomamos la medida del "yo puedo", e incluso ensayamos "maneras nuevas de ser en el mundo" (expresión con la que ya se está apuntando a una significación ontológica) (v. Du texte à l'action, 220). Por otra parte, la innovación se hace netamente práctica cuando es interpretada desde la perspectiva de la iniciativa como comienzo y como intervención en el curso de las cosas, así como en su conexión con la nietzscheana fuerza del presente ${ }^{39}$.

Finalmente, la calidad referencial del lenguaje nos ofrece una figura ontológica de lo posible a través de la relación entre lenguaje poético (en un sentido amplio que incluye la narración) y realidad. La capacidad del lenguaje para crear y re-crear nos permite ver las cosas en términos de "potencialidades" en vez de en términos de "actualidades", y nos pone en contacto con la dimensión no terminada (unfinished) de la realidad, y en esta medida, abierta a lo posible (v. "Poetry and Possibility: An Interview with Paul Ricoeur", $A$ Ricoeur Reader: Reflection and Imagination, 462) ${ }^{40}$.

\section{NOTAS}

1 Philosophie de la volonté $I$. Le volontaire et l'involontaire, Aubier, París, 1950 (será citado por el original francés ya que la traducción ha aparecido de forma fragmentaria y con escasa distribución), y Soi- même comme un autre, Seuil, París, 1990 (Si mismo como otro, Siglo XXI, México D.F., Madrid, 1996). Antes de la obra que tomamos como referencia inicial aparecieron Karl Jaspers et la philosophie de l'existence (en colahoración con M. Dufrenne), Seuil, París, 1947. y Gabriel Marcel et Karl Jaspers, Temps présent (reeditado por Seuil), París, 1948. Después de Sí mismo como otro se han publicado distintas colecciones de artículos: Lectures 1, Autour du politique, Seuil, París, 1991, Lectures 2, La Contrée des philosophes, Seuil, Paris, 1992, y Lectures 3, Aux frontières de la philosophie, Seuil, Paris, 1994. Entre los textos más recientes encon- tramos Réflexion faite, Éd. Esprit, París, 1995, Le Juste Esprit, Paris, 1995, y Critique et conviction, Éd. Calmann- Levy, París, 1995. También se recogen algunos artículos posteriores a Símismo como otro en: Kearney, R., (ed., e introd.), Paul Ricoeur: The Hermeneutics of Action, SAGE Publications, Londres, 1996.

${ }^{2}$ La senda sugerida en estas páginas constituye una versión esquemática de la recorrida en mi trabajo $L a$ Pasión por lo Posible. La polisemia de la acción en $P$. Ricoeur, Universidad de Cádiz, Cádiz, 1998 (Iibro electrónico).

3 V. El discurso de la acción, Cátedra, Madrid, 1988, 29 (traducción de "Le discours de l'action", La sémantique de l'action, D. Tiffeneau (dir.), C.N.R.S., Paris, 1977, 1 137). Bajo esa cobertura se acogen conceptos como los de agente, motivo, proyecto, intención, etc 
Introducir ahora esta noción tiene la ventaja de que nos permite comprender juntas, desde el principio, tanto la voluntad como la acción. De hecho, nuestro autor no distinguirá clara y expresamente entre una filosofia de la voluntad y una filosofía de la acción hasta sus últimas obras, y de forma marginal, lo que hay inicialmente es un desplazamiento terminológico, seguramente bajo la influencia del mundo filosófico angloamericano. De esta manera, muchos conceptos que en Le volontaire et l'involontaire caen dentro de una filosofia de la voluntad, serán progresivamente contemplados desde la perspectiva de esa red conceptual de la acción antes mencionada. El desplazamiento terminológico es, por supuesto, el reflejo de las evoluciones de la meditación sobre la acción en Ricoeur, movimientos que siguen el camino que sucintamente presento aqui, y que nos lleva desde el ambicioso proyecto explícito de una filosofia de la voluntad a una filosofia de la acción como discurso analítico-descriptivo y, finalmente, a una reflexión sobre la praxis que afirma la polisemia de la acción. A este respecto, la polisemia de la acción es ya un hecho en la práctica del trabajo de Ricoeur antes de ser tematizada por éste, provocando, en ocasiones, una cierta imprecisión terminológica o conceptual. Retrospectivamente, al explicar su interés por la acción como un resurgimiento bajo otro nombre de un problema que fue su primer campo de investigación, la voluntad, Ricoeur ha señalado las siguientes diferencias entre acción y voluntad: (1) la voluntad se define primero por su intención (el proyecto en el lenguaje de Le volontaire et l'involontaire), y la acción por su realización. (2) la voluntad puede ser solitaria, pero la acción no, ya que implica interacción e inserción en instituciones. "En este sentido, acción -concluye el autor- dice más que voluntad" (Autobiografia intelectual, 54).

- En el psicoanálisis la explicación mediante causas no es completamente separable de la explicación por intenciones y motivos. El deseo es, a la vez, causa y motivo: "por su carácter de deseabilidad, puede ser llevado a un espacio de argumentación; como fuerza, pertenece a lo que Freud llamó las «vicisitudes» de las pulsiones" (El discurso de la acción, 109).

${ }^{5}$ Finitud y culpabilidad, Taurus, Madrid, 1969 (traducción de Philosophie de la volonté II: Finitude et culpabilité $I$. L'homme faillible y Finitude et culpabilité 2. La symbolique du mal, Aubier, Paris, 1960).

${ }^{6}$ Los temas de la desproporción y la falibilidad, característicos de esta obra, ocupan incluso un lugar relativamente aislado en el conjunto de la producción de Ricoeur, como él mismo ha reconocido. Únicamente

han sido retomados, y no bajo la misma forma que tenian en Finitud y culpabilidad, en algunas de sus contribuciones a la filosofía política, y en el capitulo final de Soi-même comme un autre (donde, según el autor, habria que buscar la verdadera recuperación del tema del hombre falible) (v. Autobiografia intelectual, Ediciones Nueva Visión, Buenos Aires, 1997, 31 - traducción de Réflexion faite, París, 1995-). Aun en esta área limitada la ontología de la desproporción no reaparece como tal (v., por ejemplo, la noción de fragilidad utilizada en "Fragility and responsability", Paul Ricoeur The Hermeneutics of Action; ed., por R. Kearney)

7 "Philosophy of Will and Action", The phenomenology of action. The Second Lexington Conference on Pure and Applied Phenomenology, 1964, 7-60.

Algunos de los artículos recogidos en Historia y Verdad (Encuentro, Madrid, 1990. Traducción de Histoire et Vérité, Seuil, París, 1955; $2^{\mathrm{a}}$ ed. 1964) contienen referencias a la acción humana, concretamente la segunda sección de la segunda parte de la obra se titula "Palabra y Praxis". Pero es difícil encontrar allí algún antece dente directo de las relaciones entre lenguaje y acción desarrolladas después, tanto en lo que se refiere a la utilización del texto como paradigma de la acción cuanto en lo que concierne a las nociones de mimesis e interpretación de la acción. si bien ya aparecen la capacidad del lenguaje - la palabra dubitativa- para introducir "la dimensión de lo posible" (194), y la función creadora de la palabra poética. Lo posible se presenta en contraste con el "hay", con el hecho bruto, en cuya trama el "cuestionamiento", la palabra dubi tativa y crítica, introduce la dimensión de lo posible. Además de estas reflexiones, las más interesantes para nosotros son las que giran en torno a la palabra como modo de obrar en el artículo "Trabajo y palabra" (aparecido en Esprit en 1953), por ejemplo cuando afirma "Significar un sentido es también, de una forma muy compleja, obrar" (191). Pero esta idea acaba siendo interpretada en los términos de Le volontaire et linvolontaire, y remitiendo, en definitiva, a los análisis sobre el proyecto: "toda significación designa un vacio que el trabajo tendrá que cumplir, en el sentido con que se cumple un proyecto, un voto, un propósito". Y más adelante: "Es por este vacío de significaciones que designan y no hacen, como la palabra articula y estructura la acción"; concluyendo: "El hombre que habla pone un sentido; es su manera verbal de obrar (192).

8 V. Freud: una interpretación de la cultura, Siglo XXI, Madrid, 1985 - $1^{\text {a }}$ ed. 1970 (traducción de De 'linterprétation, essal sur Freud, Seuil, Paris, 1965), y los artículos recogidos en la segunda parte de Le conflit des interprétations, Seuil, París, 1969.

9 "The Problem of the Will and Philosophical Discourse", Patterns of the Life-World. Editado por J.M Edie, F.H. Parker y C.O. Schrag, Northwestern University Press, Evanston (Illinois), 1970

10 La intuición de la acción como texto tiene en J. Nabert uno de sus antecedentes, contribuyendo a pensar la acción en el seno de una reflexión hermenéutica: "Para emplear otro lenguaje, el de Jean Nabert, la reflexión no podría ser sino la apropiación de nuestro acto de existir, por el medio de una crítica aplicada a las obras y a los actos que son los signos de este acto de existir" (Le conflit des interprétations, 21. V., también, op. cit., 221, y Nabert, Eléments pour 
une éthique, Éd. Montaigne, París, 1971, 19, 98, y -en el Prólogo de Ricoeur- 13).

${ }^{12}$ Du texte à l'action, Seuil, Paris, 1986, 32.

${ }^{12}$ Publicado inicialmente en inglés: "The Model of the Text: Meaningful Action Considered as a Text" Social Research, 38/3 (1971), 529-562.

13 "La structure symbolique de l'action". Actes de la 14 Conférence internationale de sociologie des rellgions, Strasbourg, 1977. Secrétariat C.I.S.R., Lille, 1977, 29-50. Algunos de los elementos de este ensayo que aluden al pensamiento de $\mathrm{M}$. Weber $\mathrm{y}$ de $\mathrm{C}$. Geertz han sido desarrollados en las conferencias sobre ideología y utopía dadas en Chicago en 1971 (Ideologia y Utopia, Gedisa, Barcelona, 1989. Traducción de Lectures on Ideology and Utopia, Columbia University Press, New York, 1986).

${ }^{14}$ La dimensión semiológica establece un puente entre sistema simbólico-social y lenguaje (el sistema semiologico por excelencia), esta homología autorizaría la transposición de los métodos estructurales al campo de la acción social. Más allá de los límites estruccuralistas la dimensión simbólica de la acción junto a la utilización paradigmática del texto llevarán a Ricoeur a concebir una cierta legibilidad de la acción. La posición del autor en este punto es muy cercana a la de C. Geertz (La Interpretación de las Culturas). el simbolismo de la acción no es algo privado, sino que es una estructura establecida socialmente, la significación de la acción es, por tanto, pública. Así, la interpretación de un gesto depende de un conjunto de reglas culturales de interpretación que no son privadas (v. "La structure symbolique de l'action", 36-40, y Du texte à l'action, 244).

${ }^{15}$ La metáfora viva, Cristiandad, Madrid, 1980 (traducción de La métaphore vive, Paris, Seuil, 1975). Tiempo y narración Iy II, Cristiandad, Madrid, 1986 y 1987. y Tiempo y Narración III, Siglo XXI, Méjico, 1996 (traducciones de: Temps et récit I, II y III, Seuil, París, 1983, 1984 y 1985. La paginación será de la edición de bolsillo).

${ }^{16}$ Esta pregunta también ha orientado en nuestro país una publicación reciente que cubre una gran parte de los problemas que Ricoeur considera: Manuel Cruz, ¿A quién pertenece lo ocurrido?, Taurus, Madrid, 1995.

${ }_{17} \mathrm{~V}$. El discurso de la acción, 10, 11 y 25-27. En cuanto a otras distinciones, dos ya han sido mencionadas: la que se estableció en "Philosophy of Will and Action", y la que hacia de Le volontaire et linvolontaire una investigación meramente descriptiva: la distinción - junto a la articulación- es también patente en Símismo como otro donde la pequeña ética, como Ricoeur la denomina a veces, ocupa un lugar bien determinado en los estudios 7 a 9 . Un ejemplo bastante claro de esta relación entre un plano práctico (en la acepción restringida) y un plano ético puede apreciarse en "Aproximaciones a la persona", Amor y Justicia, Caparrós editores, Madrid, 1993, 105- 124 (v., la mención expresa del paso de un plano al otro en la pg. 119); sobre una conexión análoga entre filosofía de la acción y filosofia del derecho puede verse "Qui est le sujet du droit?", Le Juste, Éd. Esprit, Paris, 1995 29. 40.

${ }^{18}$ En este caso la acción alcanza una significación metafísica en la categoría totalizadora del actuar: hablar, hacer, narrar e imputar aparecen entonces como figuras (analógicas) del actuar. Sobre esta analogía del actuar se inserta una tentativa de reapropiación de la acepción aristotélica del ser como acto y potencia con el propósito de tener esta acepción como primer principio de un discurso sobre el actuar (v. Autobiografia intelectual, 98-99, y el estudio X de Sí mismo como otro)

I9 V., también, "Méthode et taches d'une phénoménologie de la volontê", A l'école de la Phenomenologie, Vrin, Paris, 1986.

${ }^{20}$ Sobre este punto son reveladoras las palabras del autor en su "Autobiografia intelectual", 55, y en "De la Metafísica a la moral", 97 y 98 (ambos en Autobiografia intelectual). Por otra parte, el encuentro de estas tres tradiciones no es exclusivo de Paul Rjcoeur: v. por ejemplo, J. J. Acero, "Después del análisis: significado, comprensión e intencionalidad", en Mercedes Torrevejano (coord.), La filosofia analitica hoy, Universidad de Santiago de Compostela, 1991, 9- 26, y G. Zaccaria, "Entre hermenéutica y analítica: del contraste a la colaboración", Anuario de Filosofia del Derecho X, 1993, 291-323.

${ }_{21}$ Anscombe, E. Intention, Blackwell, Oxford, 1958 (existe traducción de Ana I. Stellino: Intención, Paidós/I. C. E.- U. A. B., Barcelona, 1991).

${ }^{22}$ A Ricoeur Reader: Reflection and Imagination (Mario J. Valdés, ed.), Toronto University Press, Toronto/Buffalo, 1991, 425- 437. Publicado inicialmente en 1986 en Facts and Values. Philosophical Reflection from Western and Non-Western Perspectives (Doeser and Kraay, ed.), Martinius Nijhoff Philosophy Library, Dordrecht, 1986, 121-132

23 En "L'imagination dans le discours et dans l'action" Ricoeur afirmó, al considerar la fuerza heurística de la ficción, que el lenguaje poético expresa nuestra pertenencia profunda al mundo de la vida, y deja que se manifleste el nexo ontológico de nuestro ser con los seres y con el ser (v. Du texte à l'action, 221).

${ }^{24}$ Observemos que este verbo puede traducirse también por "vivir". Por otra parte, la dimensión ontológica de la estructura acción/pasión se complementa con la aproximación realizada por el autor en el último estudio de Si mismo como otro.

${ }^{25}$ Es posible hallar algunos elementos que favorecen la articulación entre diferentes conceptos de acción, básicamente entre el de la Teoría de la acción y el de Weber (con la incorporación del aspecto sim bólico que caracteriza una pesquisa antropológica como la de C. Geertz). La cuestión estaba allí contemplada desde el punto de vista de la conexión que la interpretación establece entre acción individual y acción social: si el significado de la acción social (Weber) depende del contexto simbólico proporcionado 
por la cultura, el de la acción individual (Teoría de la acción) está en función de su contexto motivacional. Por otra parte, la constitución semiológica del sistema social proporcionaba - $v$., nota 14 - un puente entre lenguaje y sistema simbólico-social que autoriza la transposición de los métodos estructurales (implicados en la dialéctica entre explicar y comprender) desde la esfera lingüística (texto) a la esfera práctica (fenómenos sociales) (v. op. cit., 37-40).

${ }^{26} \mathrm{~V}$. Si mismo como otro, 158 . Omitir, soportar, padecer y sufrir también son hechos de interacción: "el no- obrar es también un obrar" (ibid.).

${ }^{27}$ En Temps et récit encontramos múltiples ejemplos: "somos agentes de la hitoria sólo en la medida en que somos sus pacientes (op. cit., 391; en el mismo sentido, v., 374,375, 386, 388, etc.)

${ }^{28}$ La noción de responsabilidad, en cuanto tal, pertenece al ámbito ético- político, pero Ricoeur se ocupa en diversas ocasiones de la conexión agente/acción como elemento éticamente neutral que puede servir de sustrato a la responsabilidad (v., por ejemplo, la discusión sobre la adscripción en Sí mismo como otro, o el análisis de la acción voluntaria en Le volontaire et linvolontaire)

${ }^{29} \mathrm{~V}$., op. cit., sección II en el capitulo I de la primera parte: L'imputation du moi: SE décider.

${ }^{30} \mathrm{~V}$. "Approches de la personne", Esprit, no 160 , 1990, 115- 130 (trad., en Amor y Justicia, Caparrós Editores, Madrid, 1993, 105-124), y "Qui est le sujet du droit?", Le Juste, Éditions Esprit, París, 1995, 29 - 40.

${ }^{31}$ No me parece necesario subrayar, más allá de esta mención, que el término "pasión" no se usa aquî con el mismo sentido que cuando designa el polo pasivo de la estructura actividad/pasividad. G. B. Madison ya habló de Ricoeur como de un filósofo apasionado (v. Madison, "Text and Action: The Hermeneutics of Existence", Revue de l'Université d'Ottawa, $\mathrm{n}^{\circ} 4,1985 ., 135$ y 136). Este fondo existencial se acompaña de un rigor intelectual y de un talante equilibrado, que contribuyen a conformar la personalidad filosófica de nuestro autor.

32 La noción de libertad según la esperanza supone contemplar el sentido de la existencia (de mi existencia) a la luz de la resurrección (v., "La liberté selon l'espérance", Le conflit des interprétations, 397). De esta manera, "una hermenéutica de la libertad religiosa es una interpretación de la libertad conforme a la interpretación de la resurrección en términos de promesa y esperanza" (ibid.).

Una de las primeras monografias sobre Ricoeur (concretamente el primer libro dedicado a su pensamiento en Francia) se tituló precisamente Paul Ricoeur - ou la liberté selon l'esperance (Michel Philibert, Paul Ricoeur ou la liberté selon l'esperance, Seghers, Paris, 1871).

$33 \mathrm{Fl}$ carácter ejemplar de la iniciativa no implica la limitación del paradigma de lo posible a la acción individual. La posibilidad de la historia depende del deber de impedir que la distancia entre espacio de experiencia y horizonte de expectativa se haga excesiva:
"La implicación ética y política permanente de las categorias metahistóricas de expectativa y de experiencia es entonces clara, la tarea es impedir que la tensión entre estos dos polos del pensamiento de la historia se convierta en cisma" (Temps et récit III, 389). Esta tarea supone, por una parte, que las expectativas no apunten demasiado lejos (tal exceso es el peligro de la utopía), por tanto el horizonte de expectativa debe acercarse al presente "por un escalonamiento de proyectos intermedios al alcance de la acción" (ibíd.) Paralelamente es necesario evitar el estrechamiento del espacio de experiencia que se produce bajo la consideración del pasado como algo acabado, definitivamente cerrado, en este sentido la propuesta de Ricoeu consiste en que "hay que reabrir el pasado, reaviva en él potencialidades incumplidas, impedidas, incluso masacradas" (op. cit., 390). En lo que afecta al horizonte de expectativa la tarea se resume en hacer posible la acción (de ahí el escalonamiento de proyectos intermedios "al alcance de la acción", que eviten "desesperar de la acción" y formulen un "camino practicable" op. cit., 389-). En cuanto al espacio de experiencia podríamos decir: también el pasado es posible. El pasado no es algo cerrado y acabado de modo absoluto, reabrirlo no sólo es factible, sino que incluso constituye un deber. En ese sentido el pasado también es posible (esta misma expresión podría ser suscitada por el modelo teleológico desarrollado por el autor en la dialéctica entre arqueología y teleología contenida en sus trabajos sobre Freud)

34 Ya en Finitud y culpabilidad, Ricoeur escribe (conectando este uso de la imaginación con la eidética husserliana): "La imaginación es un instrumento indispensable en la investigación de lo posible" (op. cit., 16i).

${ }^{35}$ En alguno de sus aspectos la idea de la zona media, como marco de lo posible, sería compatible con la interpretación de la filosofía de Ricoeur como una filosofía de los límites o una filosofía "crítica" (en sentido kantiano) (v., D. F. Vansina, "Esquise, orientation et signification de l'enterprise philosophique de Paul Ricoeur", Revue de Métaphysique et de Morale, 69 (1964), $n^{\circ} 2,179-108, n^{\circ} 3,305-321$ y $F$. Henriques, "A significaçao * crítica» de Le volontaire et l'involontaire", Revista portuguesa de filosofia, tomo XLVI, Enero- Marzo, 1990, 49-84)

${ }^{36} \mathrm{~V}$., cómo la noción de iniciativa responde a esta manera de entender lo posible, conectando, por un lado, con la articulación de la actividad y la receptividad en el análisis del cuerpo de Le volontaire et l'involontaire, por otro, con la noción de poder-hacer y su correlato, el concepto de circunstancia, y finalmente con el problema de la causalidad a través de la noción de intervención de G. H. Von Wright (Du texte à l'action, 268-272).

${ }^{37}$ Uno de los más destacados especialistas en la obra de Ricoeur ha llegado a hablar del "verdadero corazón existencial y alma del pensamiento de Ricoeur" en términos próximos a esta idea de lo poși- 
ble, afirmando que la esencia de la actualidad humana es la potencialidad ("Potenciality is the essence of human actuality"), y que el ser humano siempre puede ser más y de otra manera (v. G. B. Madison, "Text and Action: The Hermeneutics of Existence", Revue de I'Université d'Ottawa, $\left.\mathrm{n}^{\circ} 4,1985,144\right)$. En el mismo artículo Madison nos ofrece su propia concepción al subrayar la presencia de la acción en la antropología de Ricoeur: "El ser humano no es sólo el "animal que habla» ("speaking animals), sino también el ranimal que actúa» (" acting animal»), no sólo animal rationale, sino también animal agens" (op. cit., 141).

Otra perspectiva que refuerza nuestra interpretación de la pasión por lo posible es la ofrecida por James R. Pambrun en "Human Action and the Future: Rerading our Theology of Creation", Kerygma (Ottawa), $21,1987,65-95$

${ }^{38}$ En su autobiografia intelectual, el autor ha recordado que la tercera parte de esa Filosofia de la Voluntad debía desplegarse en una "poética de las experiencias de creación y de recreación" ("Autobiographie intellectuelle", Réflexion fiate, 25). En el mismo artículo, el fenómeno de la innovación semántica es presentado como "un excelente ejemplo de creación" (op. cit., 44). Por otra parte, en una entrevista publicada en 1981, Ricoeur ubicó sus trabajos sobre la voluntad, sobre los simbolismos, y sobre la narración bajo la perspectiva de la creatividad, llegando a afirmar: "mi único problema desde que comencé a reflexionar es la creatividad" ("L'Histoire comme Récit et comme Pratique", Esprit, 1981, 165). Preguntado también acerca del significado de la referencia a lo poético en la expresión "Poética de la Voluntad", respondió que tenía en mente el uso griego del término poiesis, cuyo sentido es el de re-creación ("Poetry and Possibility: An Interview with Paul Ricoeur", A Ricoeur Reader: Reflection and Imagination - Mario J. Valdés, ed.- , 456) (v., más abajo, la referencia a la capacidad del lenguaje para crear y re-crear). Considerando todos estos elementos, el tema de lo posible podría ser enmarcado dentro de una reflexión general sobre la creatividad.

${ }^{39} \mathrm{La}$ virtud inaugural de la acción aproxima a Ricoeur al pensamiento de $\mathrm{H}$. Arendt quien también subraya el aspecto innovador de la acción humana. su capacidad de comenzar (v., por ejemplo, H. Arendt La condición humana, Paidós, Barcelona, 1993 201. 202).

${ }^{40}$ Paralelamente, no hay un "ego" terminado (v. op. cit., 454). Esta dimensión, que aquí es abierta por la literatura, viene a sumarse a la manifestación de lo posible en la mutua formación del ser que soy y de la acción, tal y como ya aparecía en Le volontaire et l'involontaire. 